\title{
Heliogeophysical factors as possible triggers of suicide terroristic acts
}

\author{
Pavel Grigoryev ${ }^{1}$, Vsevolod Rozanov ${ }^{3}$, Alexander Vaiserman ${ }^{2}$, Boris Vladimirskiy ${ }^{4}$ \\ ${ }^{1}$ Tavrida Humanitarian Ecological Institute, Simferopol, Ukraine; 33946@mail.ru \\ ${ }^{2}$ Institute of Gerontology, Kiev, Ukraine; vaiserman@geront.kiev.ua \\ ${ }^{3}$ Odessa National Mechnikov University, Odessa, Ukraine; rozanov@,te.net.ua \\ ${ }^{4}$ Crimean Astrophysical Observatory, Nauchniy, Ukraine; bvlad@yandex.ru
}

Received 25 September 2009; revised 3 November 2009; accepted 5 November 2009.

\begin{abstract}
Using data on suicide terroristic attacks in Israel, Iraq and Afghanistan (1062 cases 1994-2008) it was found that certain patterns of heliogeophysical factors were similar in all countries studied, and typically accompanied such acts. Geomagnetic activity significantly increased $(p<0.0001)$ at the day of attack and at the next day following attack. Interplanetary magnetic field polarity tends to change at the day before attack $(p<0.03)$ and at the day after attack $(p<0.007)$.
\end{abstract}

Keywords: Heliogeophysical Factors; Geomanetic Activity; Interplanetary Magnetic Field; Suicide Terroristic Attacks

\section{INTRODUCTION}

Variable Solar processes (flares, plasma, alternating magnetic fields etc.) have an essential influence on the parameters of the environment by the interaction with the Earth sheaths (magnetosphere, ionosphere, troposphere etc.) $[1,2]$. As shown in literature $[3,4]$, the geomagnetic disturbances and changes of interplanetary magnetic field polarity (caused by crossing by the Earth of the interplanetary magnetic field sector boundaries) are biologically effective heliogeophysical events. Depending on the level of geomagnetic disturbance, the power of alternating magnetic fields in the frequency range of $10^{-4}-10 \mathrm{~Hz}$ may vary between $0-500 \mathrm{nTl}$ globally.

Following the classical work of Alexander Thizhevskiy [5], it is commonly recognized, that heliogeophysical factors may promote social perturbances by influencing the mental state of people. Terrorism currently is a global challenge. Its prevention becomes a significant interdisciplinary problem. In our previous research, it was found that international terroristic activ- ity and heliogeophysical parameters have the same rhythmic structure in range from 2 days to 30 years [6]. The criminal activity in different regions of the former USSR correlated with fluctuations of Ap-index of geomagnetic variations [7]. A synchronism was found in the crimes of serial maniacs in USA and Russia. The majority of such crimes coincided with the increases in geomagnetic activity [8]. Over many years, significant results were received by M. Mikulecky [9]. Using historical data consisting of two time series concerning revolutions in Europe and China, and of eight time series from activities in science and arts registered from five geographic areas, it was found that revolutions culminated near to Solar maxima, while cultural flourishing is usually shown distinctly near to Solar minima. In another research, it was proved that the numbers of armed conflicts for the first half of the twentieth century were moderately associated with the global geomagnetic activity of the same year [10]. In extensive research [11], the occurrence of an approximate 10-year periodicity of the creative activity in West-European and Chinese painting, poetry and science in the period from 1400 to 1800 is shown. As a rule, the peaks of creative work in China align with those in West Europe.

However, influence of heliogeophysical factors on suicide terror attacks has never been demonstrated previously.

\section{MATERIALS AND METHODS}

To address this subject, we examined daily Solar activity (Sunspot Numbers), global geomagnetic activity (C9-index), interplanetary magnetic field (IMF) polarity at interval of \pm 5 days near the date of attack (zero day) using the superposed epoch method [12]. To reduce the possible influence of long-term large-scale variations of heliogeophysical factors, each segment of \pm 5 days' data was standardized: mean value was subtracted from initial data termwise, and the result divided by standard 


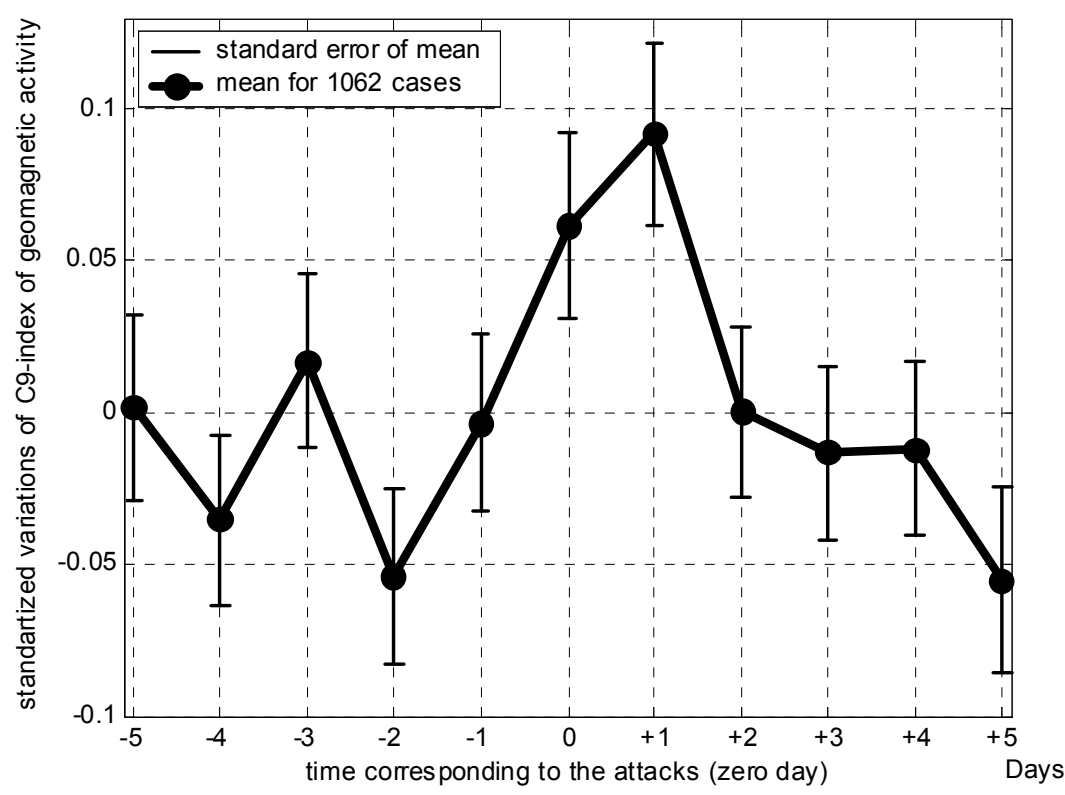

Figure 1. Changes in geomagnetic activity at interval \pm 5 days near the day of suicidal terror attack (zero day). 1062 cases are combined. Horizontal axis: time (days). Vertical axis: variations of C9-index of geomagnetic activity.

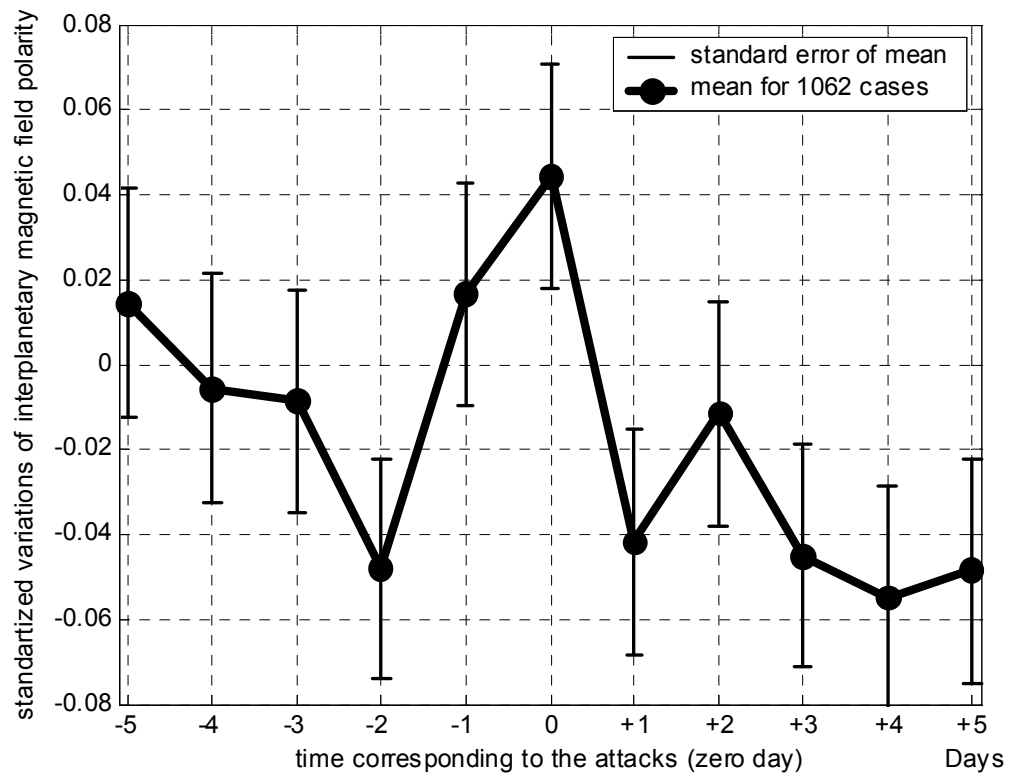

Figure 2. Changes in IMF polarity at interval \pm 5 days near the day of suicidal terror attack (zero day). 1062 cases are combined. Horizontal axis: time (days). Vertical axis: variations of C9-index of geomagnetic activity.

deviation. Statistical significance of tendencies in heliogeophysical factors near the day of attack was calculated using Wilcoxon criterion.

The data on suicide terror attacks during 1994-2008 in Israel $(n=133)$, Iraq $(n=843)$ and Afghanistan $(n=86)$ were obtained using public sources from Israel Ministry of Foreign Affairs and Memorial Institute for the Prevention of Terrorism (USA).

\section{RESULTS AND DISCUSSIONS}

No significant associations were found with Solar activity. However, in combined cohort (1062 cases) geomagnetic activity significantly increased $(\mathrm{p}<0.0001$ by Wilcoxon criterion for unpaired groups) at the day of attack and the day after attack (i.e. 0 and +1 days) comparing with other days (Figure 1). 
IMF polarity tends to change at the day before attack ( -1 day) comparing with the values in the previous day $(p<0.03$ by Wilcoxon criterion for paired groups) and at the day after ( +1 day) comparing with the values in the previous day $(\mathrm{p}<0.007)$ (Figure 2 ).

These patterns in geomagnetic activity and IMF polarity are similar in all regions studied. It can be assumed that geomagnetic variations can have an influence on a readiness to perpetrate a suicidal terror attack possibly by influencing personal suicidal tendencies of the terrorist. Moreover, recent studies support the idea that suicide terrorism and general suicidality may have some common underpinning biological and psychological mechanisms $[13,14]$.

Changes in natural electromagnetic and acoustic waves (through the action of heliogeophysical factors) affect all physiological systems of organism: brain functioning [15], cardiovascular system $[16,17]$, blood cells properties [18] etc. Moreover, biological rhythms of organism are synchronized not only by social and seasonal factors, but also by the quasi-periodical changes in heliogeophysical factors [19]. It may cause the correlation of psychic state with a geomagnetic activity. For example, in many experimental series, even among healthy individuals it was shown that reports of diminished pleasantness significantly correlate with the level of global geomagnetic activity [20]. There is also a positive relation between level of aggression in rats and geomagnetic activity [21]. In our recent study, the levels of aggression, well-being, anxiety and general motivation and activity were daily self-diagnosed and reported during February-April 2008 by 17 healthy volunteers. Significant increase of anxiety and worse well-being was observed at the time of geomagnetic disturbances and increase of anxiety and aggression at the time of changes in IMF polarity [22].

Among the possible physiological mechanisms of triggering influence of geomagnetic activity on a psychic state are: inverse relation of melatonin with a geomagnetic activity [23], redundant synchronization of brain electric activity in a temporal cortex playing an important role in the mechanisms of emotions [24], and increase of adrenalin concentration in blood [25] that may influence the level of aggression. Disturbances in acoustic noise of extremely low frequencies (infrasound) also substantially correlate with the level of geomagnetic disturbance [26]. The psychotropic influence of infrasound is well-known and confirmed through experiments: it causes nervous petulance, increase of pulse rate and a general condition of intensive anxiety [27] as well as negative influence on the state of circulatory system [28]. Changes in the interplanetary magnetic field polarity also could have an adverse influence upon the nervous system and other physiological systems of organism [29, 30], probably due to "Pc1" micropulsations of geomagnetic field, which are presented in the environment ex- actly when interplanetary magnetic field polarity is changing [31]. It was shown that Pc1 micropulsations are detrimental to health [32].

In spite of the fact that some terrorist attacks are scheduled beforehand on a definite date, a number of attacks allow various degrees of freedom in choosing an exact time by design of terrorist, because psychologically an attack is an action of individual even if the terrorist belongs to group or sect [33]. Terrorists often happen to be excitable psychopaths; most of them are in condition of chronic emotional stress [34]. It means that an essential part of terroristic attacks may be launched by the spontaneous changes in psychic state of terrorist, which can be influenced by the heliogeophysical factors, playing the role of the "last drop". This supposition is supported by results of independent observations: the geomagnetic disturbances stimulate exacerbation of depression at psychiatric patients [34]; suicides rates rise after increases in geomagnetic activity $[35,36]$.

\section{CONCLUSIONS}

It may be hypothesized that while the majority of suicide terror attacks are planned within some time-frame, changes of mental state and actualization of personal suicidal tendencies may contribute to determination of the exact date of realization of the terroristic act. Particular changes in the ambient electromagnetic and acoustical signals caused by heliogeophysical factors could promote the exacerbation of mental state and act as a trigger for launching of the suicidal-terroristic behaviour. In the majority of cases, geomagnetic disturbances and changes in interplanetary field polarity are well forecasted. So, it is possible to predict the intervals of time when a terroristic threat is higher than in average.

\section{ACKNOWLEDGEMENTS}

Project is partly supported by the Ukrainian Fundamental Researches State Fund grant F28/02-030.

\section{REFERENCES}

[1] Akasofu, S.I. and Chapman, S. (1972) Solar and Terrestrial Physics, London: Oxford University Press.

[2] Cherry, N. (2002) Schumann Resonances, a plausible biophysical mechanism for the human health effects of Solar/Geomagnetic Activity, Natural Hazards, 26, 279-331.

[3] Breus, T.K., Komarov, F.I. and Rapoport, S.I. (2005) Medical effects of geomagnetic storms, Klin. Med. (Mosk), 83(3), 4-12. (in Russian).

[4] Nikolaev, Iu.S., Rudakov, Ia.Ia., Mansurov, S.M. and Mansurova, L.G. (1982) Sectoral structure of the inter- 
planetary magnetic field and disturbances of central nervous system activity, Probl. Kosm. Biol., 43, 51-59. (in Russian).

[5] Tchijevsky, A.L. (1971) Physical factors of the historical process, Cycles, 22, 11-27.

[6] Grigoryev, P.E. and Vladimirskiy, B.M. (2006) Heliogeophysical effects on frequency of acts of terrorism, Proceedings of an International Scientific workshop "Space weather: effects on human health and biological systems". Moscow, February 17-18, 2005, 97-100.

[7] Avdonina, E.N. and Samovichev, E.G. (1995) Some heliogeophysical characteristics of a series of especially dangerous crimes, Biofizika, 40 (5), 1060-1063. (in Russian).

[8] Kitaev, N.N. and Parkhomov, V.A. (2001) About possible correlation of actions of serial sexual maniacs with the heliogeophysical factors, Bull. IGEA, 3 (28), 49-57. (in Russian).

[9] Mikulecky, M. (2007) Solar activity, revolutions and cultural prime in the history of mankind, Neuro. Endocrinol. Lett., 28(6), 749-756.

[10] Persinger, M.A. (1999) Wars and increased Solar-geomagnetic activity: aggression or change in intraspecies dominance? Percept. Mot. Skills, 88, 1351-1355.

[11] Ertel, S. (1998) Cosmophysical correlation of creative activity in the history of culture, Biofizika, 43(4), 736-741. (in Russian).

[12] Panofsky, H.A. and Brier, G.W. (1958) Some Applications of statistics to meteorology, Philadelphia: the Pennsylvania State University.

[13] Pedahzur, A. (2005) Suicide terrorism. Polity Press, Cambridge.

[14] Grimland, M., Apter, A. and Kerkhof, A. (2006) The phenomenon of suicide bombing: a review of psychological and nonpsychological factors, Crisis, 27(3), 107-118.

[15] Belov, D.R., Kanunikov, I.E., and Kiselev, B.V. (1998) Dependence of human EEG spatial synchronization on the geomagnetic activity on the day of experiment, Ross. Fiziol. Zh. im. I. M. Sechenova, 84(8), 761-774. (in Russian).

[16] Dimtrova, S., Stoilova, I., and Cholakov, I. (2004) Influence of local Geomagnetic Storms on Arterial Blood Pressure, Bioelectromagnetics, 25, 408-414.

[17] Stoupel, E. (2006) Cardiac Arrhythmia and Geomagnetic Activity, Indian Pacing and Electrophysiology Journal, 6(1), 49-53.

[18] Gurfinkel, Y.I., Voeikov, V.L., Buravlyova, E.V. and Kondakov, S.E. (2001) Effect of geomagnetic storms on the erythrocyte sedimentation rate in ischemic patients, Crit. Rev. Biomed. Eng., 29(1), 65-76.

[19] Brown, F.A. (1976) Evidence for external timing of biological clocks, An Introduction to Biological Rhythms. Academic Press, New York, 209-279.

[20] Persinger, M.A. (2004) Weak-to-moderate correlations between global geomagnetic activity and reports of diminished pleasantness: a nonspecific source for multiple behavioral correlates? Percept. Mot. Skills, 98(1), 78-80.

[21] Persinger, M.A. (1997) Geomagnetic variables and behavior: LXXXIII. Increased geomagnetic activity and group aggression in chronic limbic epileptic male rats, Percept. Mot. Skills, 85 (3 Pt 2), 1376-1378.
[22] Grigoryev, P.E., Poskotinova, L.V. and Tsandekov, P.A. (2008) Dynamics of system reaction of human organism on heliogeophysical factors, Tavrida Med. Biol. Bulletin, 11, 124-134. (in Russian)

[23] Burch, J.B., Reif, J.S., and Yoat, M.G. (1999) Geomagnetic disturbances are associated with reduced nocturnal excretion of a melatonin metabolite in humans, Neuroscience Lett., 266, 209-212.

[24] Belov, D.R., Kanunikov, I.E. and Kiselev, B.V. (1998) Dependence of human EEG spatial synchronization on the geomagnetic activity on the day of experiment, Ross. Fiziol. Zh. im. I. M. Sechenova, 84(8), 761-774. (in Russian).

[25] Gmitrov, J. and Gmitrova, A. (2004) Geomagnetic Field Effect on Cardiovascular Regulation, Bioelectromagnetics, 25, 92-101.

[26] Vladimirskiy, B.M. (1982) Atmospheric infrasonics as a possible factor transmitting the effect of Solar activity to the biosphere, Probl. Kosm. Biol., 43, 174-179. (in Russian).

[27] Didyk, L.A., Deliukov, A.A., Gorgo, Iu.P. and Semenova, I.A. (2000) Effect of extralow frequency variations of atmospheric pressure on voluntary attention parameters, Fiziol. Cheloveka, 26(4), 55-60. (in Russian).

[28] Didyk, L.A., Gorgo, Y.P., Dirckx, J.J., Bogdanov, V.B., Buytaert, J.A., Lysenko, V.A., Didyk, N.P., Vershygora, A.V. and Erygina, V.T. (2008) Atmospheric pressure fluctuations in the far infrasound range and emergency transport events coded as circulatory system diseases, Int. J. Biometeorol., 52(7), 553-561.

[29] Nikolaev, Iu.S., Rudakov, Ia.Ia., Mansurov, S.M. and Mansurova, L.G. (1982) Sectoral structure of the interplanetary magnetic field and disturbances of central nervous system activity, Probl Kosm Biol., 43, 51-59. (in Russian).

[30] Odintsov, V.I. and Konradov, A.A. (2005) Role of sector structure of interplanetary magnetic field in the geomagnetic, physical-chemical and biophysical processes, Geophysical Processes and Biosphere, 4(1/2), 5-18. (in Russian).

[31] Matveyeva, E.T. and Shchepetnov, R.V. (2007) Temporal characteristics and medical aspects of Pc1 geomagnetic pulsations, Journal of Atmospheric and Solar-Terrestrial Physics, 69, 1747-1752.

[32] Rapoport, S.I., Breus, T.K., Kozyreva, O.V., and Malinovskaia, N.K. (2006) Geomagnetic pulsations and myocardial infarctions, Ter. Arkh., 78(4), 56-60. (in Russian).

[33] Yenikolopov, S.N., Yerofeyeva, L.V. and Sokovnya, I.I. (2002) Prophylaxis of aggressive and terroristic tendencies at youth. Prosveshchenie, Moscow. (in Russian).

[34] Olshanskiy, D.V. (2004) Terrorist's psychology. Harvest, Minsk. (in Russian).

[35] Kay, R.W. (1994) Geomagnetic Storms: Association with Incidence of Depression as Measured by Hospital Admission, Br. J. Psychiatry, 164, 403-409.

[36] Grigoryev, P.Ye., Rozanov, V.A., Lubarskiy, A.V. and Vaiserman, A.M. (2005) Dependence of suicidal behaviour from the heliogeophysical factors, Archive of Psychiatry 4(43), 20-25. (in Russian).

[37] Bergiannaki, J.D., Tritakis, V.P. and Psarros, C. (1999) Environmental and geomagnetic factors in relation to selfdestructive ideation and behaviour, Proc. XX Congr. IASP, Athens, 140-141. 